\title{
La "modernidad" de la imaginación en Jagannātha Paṇḍitarāja
}

Para R. V. Joshī

Resumen: El presente artículo amplía investigaciones previas en torno al significado de la imaginación en la cultura sánscrita llamando la atención sobre un importante episodio tardío: la obra del teórico literario Jagannātha Paṇditarāja (siglo XVII). Así, con base en pasajes clave de su Rasagañgādhara, el artículo subraya la originalidad de la teoría de Jagannātha sobre la imaginación a la luz de las ideas de historicidad, subjetividad y relatividad, sugiriendo además su deuda con el inusual horizonte intelectual de nuestro autor: bajo el auspicio de la corte mogola.

Palabras clave: Jagannātha Paṇditarāja, imaginación, literatura sánscrita, imperio mogol.

Abstract: This paper expands previous research on the meaning of the imagination in Sanskrit culture, calling attention to an important late episode: the work of the literary theoretician Jagannātha Paṇditarāja (XVII). Thus, based on key fragments of his Rasaganigādhara, the paper underscores the originality of Jagannātha's theory on the imagination in the light of the ideas of historicity, subjectivity and relativity, suggesting its debt with this author's unusual intellectual horizon: under the auspices of the Mughal court.

Key Words: Jagannātha Paṇditarāja, imagination, Sanskrit literature, Mughal empire.

\section{INTRODUCCIÓN}

Este artículo amplía y complementa la investigación cristalizada en mi libro La mirada anterior. Poder visionario e imaginación en India antigua, publicado no hace mucho (México, UNAM, 2017). Ahí exploré el significado de la imaginación como tema de análisis en la India sánscrita y en ese contexto presenté un itinerario de poco más de dos milenios, del poder visionario védico hasta las técnicas contemplativas tántricas, pasando por las reflexiones que sobre la materia produjeron filósofos y teóricos literarios a lo largo del periodo clásico. Sin embargo, el libro no agota un tema tan variado y complejo; importantes episodios quedaron fuera y en general su contenido puede transmitir la idea de que la historia de la imaginación en India antigua termina con figuras como Rājaśekhara y Abhinavagupta, en el siglo XI. No es así. Por ejemplo, por el sendero de la poética el debate en torno a la imaginación se prolongó por casi un milenio, alcanzando un original desenlace en la obra de Jagannātha Paṇditarāja, tema del presente artículo.

El propósito aquí es pues solventar parcialmente las limitaciones lógicas de La mirada anterior, confirmando la persistencia de un importante aspecto de la cultura sánscrita más allá 
del horizonte clásico y, de hecho, en una atmósfera por completo inédita: en el esplendor del imperio mogol (siglos XVI-XVII).

Ahora bien, para comprender mejor la aportación de Jagannātha a nuestro tema, es necesario decir algo sobre la añeja tradición que sobre la materia precede a nuestro autor y con la que éste se identificó de manera explícita. Así, en la siguiente sección resumo lo que expuse en La mirada anterior en torno al desarrollo de la tradición poética sánscrita y las principales ideas que ésta articuló a propósito de la imaginación. Tras ello, el artículo se adentra en el inusitado horizonte intelectual de Jagannātha (sección 3), notando la peculiar relación que desde dicho horizonte nuestro autor estableció con el pasado, en especial con la propia tradición poética sánscrita (sección 4), y, finalmente, apreciando el contenido y originalidad de su teoría sobre la imaginación (secciones 5-7).

\section{LA IMAGINACIÓN EN INDIA ANTIGUA: DE LA POESÍA A LA RELIGIÓN}

El tema de la imaginación en la India se remonta a los fenómenos de la inspiración y el poder visionario (dhīh) en la antigua cultura sacrificial védica. En particular, las dotes imaginativas de los rșis, los míticos sabios-sacerdotes, se irguieron desde una época temprana como un legado perdurable y proteico, capaz de adquirir nuevas identidades y responder a necesidades inéditas. La imaginación forma, pues, parte de este complejo mecanismo de continuidad en medio de la discontinuidad. Tal mecanismo cobró vida sobre todo en la forma de una retórica arcaizante abocada a trasladar al presente los valores de la tradición, así como en la necesidad de legitimar el cambio y la novedad creando un vínculo con la antigua cosmovisión. En el caso de la imaginación, este movimiento de ida y vuelta gira alrededor del sentido de la vista o, más exactamente, del uso de motivos visuales para fundamentar el proceso creador. La responsabilidad léxica para designar esa facultad recayó en la palabra pratibhā, que heredó el campo semántico de dhịh, el don por antonomasia del sacerdote inspirado en el periodo védico. Así, estrechamente vinculada con los fenómenos de la luz y la vista, pratibhā evoca, como dhīh, el acto por el que algo se manifiesta de manera espontánea ante el ojo de la mente (Gonda, 1984, p. 318). ${ }^{1}$ Numerosos testimonios dan cuenta de la pervivencia de los antiguos ideales visionarios a través de la pratibhā del poeta. Entonces, más allá de las diferencias en otros temas, todos los tratados de teoría literaria sánscrita coinciden en la íntima relación que guardan, por un lado, la actividad poética (kāvya), y, por el otro, la pratibhā del poeta. "La poesía es el don espontáneo de aquel que posee pratibhā", ${ }^{2}$ celebró Bhāmaha en su

\footnotetext{
${ }^{1}$ Dentro de la propia tradición, el uso más antiguo de pratibhā al parecer pertenece a Yāska, Nirukta 4.6 y 13.18.

2 Todas las traducciones del sánscrito son mías.
} 
Kāvyālañkāra (1.5), el tratado más temprano sobre la materia que nos ha llegado (siglo VII), inaugurando un consenso al que se sumaría una larga lista de autores.

Apenas dos siglos después de Bhāmaha, dicho consenso alcanzó dimensiones insospechadas gracias el propio desarrollo de la teoría literaria sánscrita, sobre todo una vez que ésta comenzó a prestar menos atención a las cualidades formales del lenguaje literario y más al efecto que éste produce en la audiencia. Como se sabe, el artífice de este importante giro fue Ānandavardhana, quien, a diferencia de sus predecesores, defendió el valor de la creación poética en función no tanto de sus cualidades formales sino de la realización de una meta más universal, a saber, la comunicación de un sentimiento (rasa). Así, concluyó que el poder que subyace al sentido que la literatura transmite es la "sugestión" (vyāñjakatva), o dicho de manera más literal la "manifestación" (vyañjana) de un sentido no explícito (vyañgya), y cuya forma más pura o plena él llama dhvani, el “alma de la poesía” (Dhvanyāloka 1.1).

El significado de pratibhā en la obra de Ānandavardhana necesariamente estará, pues, determinado por esta reorientación de la comunicación poética desde sus antiguos fundamentos formalistas hacia una teoría completa del sentimiento estético. Así, imaginar será ahora sobre todo la capacidad para comunicar estéticamente un contenido subjetivo, y no tanto la habilidad para transmitir belleza a través de un manejo diestro de figuras retóricas. Liberada de las demandas formalistas, la imaginación constituye ahora un medio privilegiado para percibir el entretejido afectivo de la realidad y evocarlo. Más aún, de esa atención al mundo dependerán las cualidades de frescura y originalidad que distinguen a la buena literatura. Y si las posibilidades de la imaginación son las posibilidades de la experiencia humana, entonces su poder es ilimitado: "La imaginación poética se extiende sin fin por el sendero de la evocación..." (Dhvanyāloka 4.1).

Tal vindicación, desde la teoría literaria y la praxis poética, de la actividad imaginativa tuvo un impacto definitivo en otros ámbitos, en especial en el religioso. Esa extrapolación aparece consumada en la obra de Abhinavagupta, no casualmente autor de un lúcido comentario a la obra de Ānandavardhana. Sin embargo, la extrapolación completa de la imaginación hacia la religión y la mística aparece desplegada en su obra filosófica y teológica. Alí, a propósito de su doctrina sobre la unidad absoluta de la conciencia, Abhinavagupta sostendrá que el poder de esa conciencia para devenir en todas las formas posibles, puede describirse asimismo como el poder para imaginar el universo y cada objeto en él. Desde la percepción de objetos que considero externos hasta los desatinos de la fantasía, el mecanismo es el mismo y se fundamenta en la libertad de la conciencia para proyectar este mundo plural dentro de sí misma, como una pintura sobre un lienzo. Nada acontece fuera o al margen de 
esta conciencia no dual, y en ese sentido cualquier realidad puede entenderse como una imagen dentro de la conciencia. Dicho de manera muy simple, si la deidad es por definición una conciencia dinámica a la que nada es extrínseco, entonces nada ejemplifica mejor su naturaleza que la actividad de la imaginación. Por ende, cualquier relación de objetividad (exterior o mental, sensible o conceptual, afectiva o intuitiva, etc.) en realidad presupone una relación imaginativa.

Así las cosas, si en el ámbito poético Ānandavardhana decía que pratibhā es un poder ilimitado en virtud de su capacidad para crear realidades "inéditas" (apūrva) y "originales" (nava), Abhinavagupta no dudará en afirmar que tales son justamente los atributos de la manifestación libre y espontánea de la conciencia, reuniendo así su poética de la imaginación y su doctrina sobre la agencia absoluta, no dual, de la conciencia. Ello explica por qué Abhinavagupta predica este poder, pratibhā, tanto del poeta como de la deidad, homologando indirectamente a ambos y en última instancia poesía y mística (véase Locana ad 1.19 o Tantrāloka 1.2).

Esta divinización de la imaginación tiene desde luego una última e importante secuela, que permite el paso de pratibhā a otra noción igualmente importante: bhāvanā. Y es que si el Absoluto tiene como principal atributo la manifestación imaginativa, dentro de sí, de la realidad entera, entonces en cierto sentido la salvación depende de la capacidad del individuo para acoger en su propio corazón, a la manera del receptor sensible de una pieza literaria, el impulso imaginativo de Dios hasta fundirse con él. Poetas y yoguis nos ofrecen con su ejemplo un camino a la salvación porque ambos encarnan esa comunión íntima con el poder creador de Dios, la capacidad para recibir y sostener el impulso imaginativo de Dios hasta reconfigurar (bhāvayati) la realidad entera desde la perspectiva de la propia conciencia, ahí donde lo invisible precede a lo visible, donde la imagen es más real y la imaginación la forma más elevada de conocimiento. De este modo, para decirlo con Edwin Gerow, "con el artista convertido en practicante religioso, la persistente religiosidad de las artes indias regresa sobre sí misma" (1997, p. 322).

\section{JAGANNĀTHA PAṆITITARĀJA: LA CULTURA SÁNSCRITA BAJO EL AUSPICIO DE LA CORTE MOGOLA}

La trayectoria que brevemente he referido y, más importante aún, el carácter concluyente que ésta alcanzó en la obra de Abhinavagupta, prevaleció en los siglos subsecuentes influyendo en el desarrollo de la teoría literaria sánscrita a lo largo del periodo premoderno. Así, teóricos posteriores, comenzando con Mammața en el siglo XII, aceptaron la autoridad de la línea de pensamiento que va de Ānandavardhana a Abhinavagupta. Esta tendencia se prolongó hasta el 
último gran teórico de la poética sánscrita, Jagannātha, quien hizo suyo el legado y respondió a él asumiendo su valor canónico: Ānandavardhana fue quien "fijó el rumbo que deben seguir los teóricos literarios" (Rasagañgādhara, p. 241), proclamó en el siglo XVII, contribuyendo a diluir el espíritu de debate que animó a la poética sánscrita en la época del propio Ānandavardhana (McCrea, 2009, p. 8ss). En términos generales, Jagannātha abrazó, pues, las preocupaciones, métodos y respuestas que por siglos dieron identidad a la teoría literaria sánscrita; más importante aún, con dicha reiteración afirmó la pretensión de sus antecesores de habitar un universo expresivo atemporal, donde pasado y presente pueden coexistir (Pollock, 2013, p. 96; Pollock, 2001르, p. 404).

Sin embargo, como se sabe, el pasado sólo puede pensarse desde el presente, incluso en una tradición como la sánscrita, obsesionada con restarle fuerza al cambio histórico. En efecto, casi un milenio separa a la India que comenzó a vindicar poéticamente el poder de la imaginación de la India en la que vivió y escribió Jagannātha; más de medio milenio a la India que radicalizó esa vindicación por el sendero de la mística de la India en la que la cultura sánscrita alcanzó su último esplendor bajo el patronazgo mogol.

Las dudas nos asaltan. ¿Pese a tal distancia, se reduce la aportación de Jagannātha a reproducir la herencia recibida? ¿También en su caso el valor más alto de la imaginación ha de hallarse en el paso del poder creador a la absorción contemplativa, y por lo tanto en el paso de la literatura a la religión? ¿O hay en cambio indicios de que el inusitado horizonte intelectual de su época de algún modo alcanzó expresión en su obra, aun si sólo de manera implícita? Y si así fue, ¿en qué sentido?, ¿con qué efecto sobre su tratamiento de la imaginación?

Para descubrir cuál puede ser ese elemento de discontinuidad en medio de la continuidad, y contar así con mejores fundamentos para apreciar el aporte de Jagannātha al tema de la imaginación, es necesario bosquejar primero el entorno cultural de nuestro autor, reparando en el tipo de premisas y aspiraciones que, me parece, dicho entorno alentó.

Jagannātha fue un poeta cortesano, la misma condición que permitió el trabajo de un sinfín de intelectuales sánscritos antes de él. Empero, la comparación presenta una discrepancia apenas recordamos las coordenadas espaciotemporales de la corte que patrocinó su carrera: Delhi, siglo XVII, en el esplendor del imperio mogol. ${ }^{3}$ Por sí solo, y omitiendo por ahora los detalles, el dato desafía la imagen del intelectual sánscrito como una figura cerrada y, en un sentido más amplio, pone en entredicho la imagen del encuentro entre el hinduismo y el

\footnotetext{
3 Al parecer Jagannātha recibió además el patronazgo de dos gobernantes hindús, Jagatsiṃha (Udaipur) y Prāṇanārāyaṇa (Kāmarūpa), como se desprende de dos encomios de su autoría, respectivamente el Prānābharaṇa y el Jagadābharana. Sin embargo, por su propio testimonio sabemos que produjo la mayor parte de su obra durante su estancia en la corte mogola.
} 
islam como uno de oposición permanente (Truschke, 2012, cap. 1; Chaudhuri, 1942, introducción; Friedmann, 1975, pp. 215-217; Halbfass, 2013, cap. 2.). El patronazgo mogol a la cultura sánscrita en realidad culmina un largo proceso de interacción cultural y científica que data de las primeras incursiones musulmanas en la India. Así, de Akbar a Dārā Shukōh, los mogoles no sólo fueron generosos patrones de la producción textual sánscrita, sino que reconocieron su cosmopolitismo y vitalidad como parte de un ambicioso proyecto de integración política y cultural. En efecto, entre 1570 y 1650, intelectuales sánscritos con diferentes filiaciones, en especial jainas y brahmanes, sirvieron en la corte mogola no sólo como literatos, sino asimismo como astrólogos, músicos, guías religiosos e informantes (Truschke 2012, pp. 32-33).

Aunque la mayoría, en especial los brahmanes, evitó convertir su experiencia imperial en tema literario o explorar en sánscrito su interacción con el islam, ello no fue impedimento para aceptar el patronazgo mogol, participar plenamente de la vida en la corte y, quizá lo más notable, componer textos para el consumo de ésta, ya sea encomios completos (praśasti) o versos sueltos (muktaka) redactados conforme a las convenciones que la literatura sánscrita empleó por siglos para estetizar el poder regio (Truschke 2012, pp. 56-57).

Jagannātha no fue la excepción. Pese a descender de una familia ortodoxa del sur de la India ${ }^{4}$ y haber recibido una educación brahmánica tradicional, viajó hasta Delhi y se puso al servicio del emperador Shāh Jahān, cuyo patronazgo reconoció y ensalzó poéticamente ${ }^{5}$ y de quien recibió el título con el que hoy se le conoce: "Rey de los sabios" (pandititarāja). ${ }^{6}$

Este intercambio constituye un verdadero hito que da cuenta de las profundas transformaciones que la cultura literaria sánscrita experimentó, ya no sólo debido a su propia dinámica interna, sino, de un modo más radical, debido a su cada vez más estrecha interacción con el horizonte paralelo del islam. Al respecto, nada retrata mejor la inmersión de Jagannātha en el horizonte multicultural de su época y lo que ello significó para la tradición sánscrita, que la

\footnotetext{
${ }^{4}$ Se supone además que nació en el seno de la comunidad vaișnava conocida como Puștimārga. De hecho, los testimonios indican que Vallabhācārya, el carismático fundador del movimiento, fue su bisabuelo en la línea materna (Athavale, 1968, pp. 415-416).

${ }^{5}$ A manera de ejemplo, véase entre otros versos Bhāminīvilāsa 4.32b: "Su primera juventud transcurrió bajo la protección del emperador de Delhi", y Panḍitarājakāvyasanigraha, p. 190, verso 579: "[Únicamente] el soberano de Delhi o bien el soberano del universo tienen el poder de satisfacer [nuestros] deseos". Al parecer Jagannātha arribó a Delhi durante el reinado de Jahāngir, el padre de Shāh Jahān, a quien también habría servido (Pandịtarājakāvyasañgraha, p. 200, verso 95). Mucho se ha especulado si Jagannātha sirvió asimismo a Dārā Shukōh, el primogénito de Shāh Jahān. Sharma rechaza esta posibilidad (Paṇ̣̂itarājakāvyasañgraha, pp. iv, viii); Pollock parece respaldarla (2003, p. 96, y 2001a, p. 408). En cualquier caso, la tradición cuenta que afectado por la lucha dinástica entre Dārā Shukōh y su hermano Aurangzeb, Jagannātha decidió abandonar la corte y refugiarse en Benares.

${ }^{6}$ Sabemos esto por su propio testimonio en un breve panegírico dedicado a Āsaf Khān, visir de Shāh Jahān, a propósito de una exitosa visita a Cachemira: "Condecorado con el título 'Rey de los sabios' con el que lo favoreció el Excelentísimo Soberano Universal Shāh Jahān, el sabio Jagannātha escribió esta narrativa titulada Āsaphavilāsa" (Paṇ̣itarājakāvyasanigraha, p. 85)..
} 
historia, narrada en primera persona, sobre su supuesto romance con una mujer musulmana de nombre Lavañīi ${ }^{7}$ Reproducida en varias antologías modernas, la historia presenta a Jagannātha no sólo como testigo de la realidad mogola, sino él mismo como referente de una vivencia tan profunda como el amor. El relato no sólo da cuenta de una situación inédita entre los hablantes del sánscrito; es muy probable que esté inspirado en motivos literarios persas (Pollock, 2001b, p. 20; 2003, p. 98; 2001ª , p. 409).

Pero más allá de esto e incluso más allá de la veracidad histórica del romance, lo que hay que destacar -en virtud de sus repercusiones para nuestro tema aquí- es el uso del sánscrito como vehículo de expresión personal. La historia de Lavañgī no es el único ejemplo. Los detalles que Jagannātha ofrece, de nuevo en sánscrito y en primera persona, sobre la muerte de su primera esposa y un hijo tampoco tienen parangón dentro de la literatura sánscrita (respectivamente Bhāminīvilāsa 3.3-10 y Rasagañgādhara, p. 88).

Al respecto puede especularse que como consecuencia de las circunstancias a las que se enfrentó la cultura sánscrita durante los siglos XVI y XVII, ésta se vio obligada a articular no sólo un nuevo tipo sensibilidad hacia el otro musulmán, sino además, en ese mismo proceso, a reconfigurar la propia identidad, en este caso sancionando como correcto el uso del sánscrito para comunicar valores subjetivos y temporales. Del singular horizonte histórico de Jagannātha llegamos así a un importante aspecto del horizonte conceptual que enmarca su reflexión sobre la imaginación.

\section{SUBJETIVIDAD E HISTORICIDAD DE LAS IDEAS}

La estetización de la historia personal o, dicho de otro modo, la ampliación del campo expresivo de la literatura sánscrita a la esfera individual, en última instancia refleja un énfasis inédito en la subjetividad. No es extraño entonces que la obra de Jagannātha esté salpicada de referencias personales que revelan una aguda conciencia autoral y, por lo tanto, un distanciamiento respecto a la arraigada tendencia de los pensadores sánscritos a ocultar su identidad en la tradición que legitima su actividad, por definición impersonal. Una y otra vez, Jagannātha se presenta por su nombre para vanagloriarse de sus logros y minimizar los de sus antecesores. ${ }^{8}$ Esta actitud se refleja asimismo en la tendencia a usar citas propias a fin de ilustrar sus

\footnotetext{
${ }^{7}$ La historia se desprende de ocho estrofas atribuidas al poeta y reunidas por Sharma bajo el título "Eulogio a Lavañī̄" (Paṇụitarājakāvyasañgraha, p. 190).

${ }^{8}$ Por ejemplo: "La obra de Paṇụitarāja no tiene parangón en el mundo entero" (Bhāminīvilāsa 4.32). También cuando Jagannātha se compara con el portentoso Monte Meru en el mar de la poética: a diferencia incluso de los "peces más formidables" (timindra), es decir, de los maestros más eminentes, sólo él puede extraer los tesoros que yacen en sus profundidades (Rasagañgādhara, p. 2, estrofas introductorias).
} 
argumentos, distanciándose de una práctica que, al menos desde el siglo VIII, privilegió las citas de autores consagrados. ${ }^{9}$

Esto sugiere que la implicación más obvia -y de mayor relevancia para nuestros fines aquí- es la que tiene que ver no con el presente per se sino con la relación entre el presente y el pasado. Desde luego, Jagannātha no fue el primero. Comenzando en los siglos XIII y XIV, tal vez incluso antes en figuras como Abhinavagupta, se observa una tendencia a subrayar los logros intelectuales del presente de un modo que va más allá de su instrumentalización como medio para recuperar y afirmar el pasado; la sensación que se respira es más bien de novedad. Entre los lógicos y los gramáticos primero, y más tarde también en la teoría literaria, incluido Jagannātha, esta tendencia finalmente adquirió consistencia léxica a través del uso de categorías temporales para calificar a tal o cual pensador, o para distinguir a un oponente respecto a las ideas propias. Las diversas escuelas fueron así juzgadas según su modernidad o antigüedad; la postura de teóricos más actuales (navya, arvāc, navīna, ādhunika) fue contrastada con la de pensadores previos (pracīna, prācya).

De nuevo, a primera vista, el esfuerzo parece estar encaminado a poner de cabeza el modelo clásico, donde el pasado supera intelectual y moralmente al presente, y el conocimiento se construye con base en la autoridad de un canon que relega a segundo plano tanto las condiciones históricas de su producción como la identidad de sus agentes, y cuya mejor expresión es la tradición exegética y de comentarios (AUTOR, 2013). Sin embargo, en la práctica se trata de algo más complejo que una simple resignificación del presente como indicio de perfeccionamiento intelectual; antes bien, el modelo acepta grados intermedios y matices, y la línea divisoria entre lo antiguo y lo moderno no siempre es clara. Encima, novedad y tradición pueden convivir en un mismo autor, calificar un mismo periodo o tener connotaciones positivas o negativas dependiendo del contexto y del tema de que se trate (Pollock, 2001b, pp. 5-10).

Este tipo de discurso, con sus flexibles criterios, enmarca la relación que Jagannātha estableció con la teoría literaria sánscrita y, por lo tanto, como veremos, con el tema de la imaginación. En un artículo reciente, Gary Tubb y Yigal Bronner ofrecen varios ejemplos de esa compleja relación e intentan discernir su posible lógica. En este contexto, llaman la atención sobre el uso que Jagannātha da a la expresión vastutas tu ("pero en última instancia"), entendida como indicador de una actitud de mayor exigencia teórica frente a la pluralidad e historicidad del saber. Aquí su conclusión:

\footnotetext{
9 "A manera de ejemplo, incluí en el libro poesía inédita de mi autoría y de nadie más" (Rasagañgādhara, p. 2, estrofas introductorias). De hecho, el Bhāminivilāsa puede verse como una colección con fines didácticos, usada para ilustrar las doctrinas expuestas en el Rasagañgādhara, pero presentada por separado a fin de dejar en claro quién es su autor: "Ante la posibilidad de que algún innoble bastardo robara mis alhajas poéticas, hice para ellas este joyero" (Bhāminīvilāsa 4.33).
} 
Claramente, por lo tanto, lo que determina el orden de su presentación no es una preocupación cronológica, sino más bien un interés en la interrelación de las ideas [...] En vez de buscar probar que su perspectiva contiene la última palabra [...] lo que le interesa es mostrar el modo como podrían interactuar diferentes ideas [...] Definitivamente, su enfoque está en la historia de las ideas (2008, pp. 626-627).

En efecto, lo que observamos con Jagannātha, siguiendo la huella de otros antes de él, pero con mayor intensidad que cualquiera en virtud de la singular atmósfera que auspició sus indagaciones, y lo que debió significar su inmersión en esa atmósfera en términos de una sensibilidad sin precedentes a los fenómenos de alteridad, subjetividad y pluralidad del conocimiento, lo que observamos, decía, es una tematización del mecanismo completo de continuidad-discontinuidad que, por un lado, crea una resistencia hacia la arcaizante retórica sánscrita, y, por el otro, sobre ese mismo patrón, se permite un mayor refinamiento en sus contenidos e implicaciones. La voluntad diacrónica a relativizar la pureza teórica que otorga el pasado y distanciarse del espíritu sincrónico del saber sánscrito, no cancela, por lo tanto, la posibilidad de explorar nuevas formas de interrelación entre pasado y presente, así como proyectar diferentes identidades temporales; de hecho, de algún modo lo demanda. Para Jagannātha ni la nobleza del pasado se traduce en obediencia ciega, ni la vitalidad del presente justifica una emancipación infundada. Es necesario un proceso de racionalización que integre ambos momentos, notando sus múltiples grados de interacción y complementariedad. Y lo que Jagannātha dijo sobre la imaginación frente a las enseñanzas que en la materia produjo la milenaria poética sánscrita, no se entiende cabalmente sin este par de elementos: subjetividad e historicidad. Es momento de averiguar en qué sentido con base en pasajes clave de su obra maestra, el Rasagañgādhara.

\section{EL ARTE DE dAR RAZONES O LA SECULARIZACIÓN DE LA IMAGINACIÓN CONTEMPLATIVA} (BHĀVANĀ)

Jagannātha abre su Rasagañgādhara con una sobria definición de poesía que evidencia la herencia del giro iniciado por Ānandavardhana, con su énfasis en el contenido, no en la forma: "Poesía es el lenguaje que transmite un significado bello" (Rasagañgādhara, p. 5). A esta adherencia canónica sigue sin embargo un novedoso proceso de racionalización que pone de manifiesto la influencia del discurso causal de la lógica (nyāya). El tipo de lenguaje que Jagannātha emplea, saturado de sufijos abstractos, pone de manifiesto la seriedad de sus pretensiones: crear una especie de meta-discurso, fundado en categorías universales y que sea capaz de responder no sólo a las exigencias teóricas de la ciencia poética sino además a las de 
un tribunal más amplio e imparcial, y por ello con mayor poder legitimador: el de la epistemología (Shulman, 2012, p. 99).

La nueva exigencia es encauzada sobre todo a través de un esclarecimiento semántico de los términos clave o, en un sentido más técnico, a través de una exposición de los elementos particulares (viśeșaṇa) que componen la definición general (sāmānyalakṣaṇa) (Sjoman, 1981, pp. 372-373). Es pues necesario definir a su vez la "belleza" (ramaṇiyatā), el elemento que distingue a la poesía de otras formas de comunicación lingüística (śabda, artha). Leemos entonces: "Y la belleza es la propiedad de ser el objeto de un conocimiento que produce un placer extraordinario" (Rasagañgādhara, p. 6). La representación epistemológica del fenómeno literario se robustece así a partir de una redefinición de la fórmula original que hace explícito al sujeto cognoscente (Sjoman, 1981, p. 380). La experiencia poética está fundada, como cualquier otra, en una relación sujeto-objeto. Al mismo tiempo, sin embargo, la aprehensión del objeto "poético" no coincide con un juicio gnoseológico (verdadero/falso) o moral (bueno/malo), sino estético. Como sea, es claro que para Jagannātha el juicio estético se produce no al margen sino dentro de los límites del mecanismo cognitivo en general, y en ese sentido, la estética depende de la epistemología: en ella alcanza autonomía. Este novedoso acercamiento será, insisto, decisivo cuando lleguemos al tema de la imaginación.

Antes es necesario precisar algunos términos más. Por ejemplo, a fin de discernir con mayor rigor lo que distingue al conocimiento poético, conviene decir algo sobre el calificativo "extraordinario" (lokottara). Al respecto Jagannātha afirma que se trata de un sinónimo del estado de intenso asombro (camatkāratva) que sin más le sobreviene al sujeto, como lo sugiere la sonoridad onomatopéyica de la palabra camatkāra, aportación de Abhinavagupta a la estética sánscrita: "Ahora bien, con el carácter extraordinario que define al placer [estético] en realidad me refiero a un estado de asombro" (Rasagañgādhara, p. 6).

Es al preguntarse a su vez por la causa detrás de este estado de asombro que Jagannātha introduce el tema de la imaginación. Como es de esperar, también en este caso el efecto tiene un mayor peso causal que el origen, y así el término elegido es bhāvanā y no pratibhā. Leemos: "La causa a su vez [del estado se asombro] es un tipo especial de bhāvanā consistente en una atención [imaginativa] sostenida" (Rasagañgādhara, p. 7).

La idea de una "atención sostenida" (punaḥ punar anusandhāna) evoca el proceso de universalización imaginativa tan caro a autores como Bhaț̣anāyaka y Abhinavagupta. Con esto, Jagannātha deja en claro que la experiencia de asombro que distingue a la experiencia poética y en general al conocimiento estético de algún modo depende de bhāvanā, que en ese sentido, repito, cumple una decisiva función causal. De hecho, bhāvanā sustituye aquí a jñāna en la 
definición de "belleza" (ramaṇiyatā), de modo que ésta puede reformularse como sigue: "La belleza es la propiedad de ser el objeto de una bhāvanā que produce un placer extraordinario". Por un lado, la realidad estética sólo puede experimentarse a través de este poder cognitivo que Ilamamos bhāvanā; por el otro, esta bhāvanā es "especial" (viśeșa) en función precisamente de su contenido estético. En el fondo, Jagannātha es consciente de la doble identidad semántica de bhāvanā, con su carga contemplativa e imaginativa, y en cierto sentido saca provecho de ello al aplicar el término al conocimiento que se produce bajo las particulares circunstancias de la poesía (Shulman, 2012, p. 100). Por último, el sustrato etimológico de la palabra también está presente. Derivada del causativo de la raíz -bhū, la acepción más elemental de bhāvanā remite al proceso por el que algo se impone en nuestra conciencia al imaginarlo intensamente.

Hasta aquí todo luce como una reiteración del legado de los teóricos de la resonancia y el sentimiento (dhvani, rasa), la tradición de Abhinavagupta, que al poner en el centro el proceso de recepción consiguió superar el formalismo de los pioneros en la materia. Esta continuidad podría hacernos olvidar el peculiar marco teórico que la envuelve. ¿Qué papel juegan en este caso las sucesivas aclaraciones epistemológicas de Jagannātha? ¿Se trata de un simple recurso retórico o de algo más?

Para averiguarlo tenemos que aguardar hasta la larga sección dedicada a la teoría del rasa, donde, como es de esperar, bhāvanā reaparece. Redactada bajo el espíritu enciclopédico de Abhinavagupta, la sección resume y revisa más de una decena de interpretaciones en torno al canónico rasasūtra del Nātyaśāstra. Sin embargo, la presentación de Jagannātha no es jerárquica; antes bien, las doctrinas aparecen en su complejidad diacrónica y reciben diferentes valores temporales sin evidenciar una adherencia única o definitiva.

El interés de Jagannātha por la historia de las ideas se pone asimismo de manifiesto en su recuento del concepto de universalización imaginativa (bhāvakatva), que, en el caso de Abhinavagupta culmina en una tercera función, de gozo o deleite (bhogakrttva), comparable a la realización del Absoluto. Jagannātha no se pronuncia abiertamente a propósito de esta implicación que abandona el terreno de la poética para internarse en el de la mística y la soteriología. Su descripción, en cambio, mantiene de principio a fin un tono neutral (Rasagañgādhara, pp. 58-59).

Sin embargo, esta imparcialidad esconde una estrategia más compleja. Como en las primeras páginas del libro, la misma se despliega a través de una redefinición de los conceptos en juego a la luz del mecanismo que rige al conocimiento en general. En un giro que recuerda 
las suspicacias de algunos filósofos sánscritos respecto a la imaginación, ${ }^{10}$ Jagannātha asume que también bhāvanā debe responder, para conservar su legitimidad, ante el tribunal de la epistemología. Es necesario pues preguntar por aquello que "en última instancia" (vastutas) subyace al fenómeno de universalización imaginativa. De este modo, la estructura que primero es sancionada como válida es ahora sometida a un nuevo tipo de escrutinio, exigencia de los nuevos tiempos, como elocuentemente lo establece Jagannātha al ponerla en boca de ciertos teóricos "modernos" (navya). Aquí el inusitado pasaje:

Sin embargo, los [teóricos] modernos [opinan que] la experiencia estética, es decir, la indefinible (anirvacanìya) manifestación sensible de Śakuntalā, etc., como objeto del deseo y demás [emociones], se produce por el influjo de un error [cognitivo] que el espectador empático desencadena en la forma de un tipo especial de bhāvanā, velando así su propio ser con un Dușyanta imaginario, tal como debido a la ignorancia, una esquirla de nácar [es confundida] con un pedazo de plata (Rasagañgādhara, p. 60).

El discurso puede sonar ambiguo. Por un lado confirma lo que la teoría literaria sánscrita venía sospechando desde el siglo IX: sin imaginación receptiva no hay experiencia estética; la degustación estética se produce cuando el receptor sensible (sahrdaya) se identifica imaginativamente con los personajes representados, en este caso Śakuntalā y Duṣyanta, los protagonistas del célebre drama de Kālidāsa, El reconocimiento de Śakuntalā (Abhijñānaśakuntalā). Todo bien hasta aquí. Por el otro, sin embargo, el pasaje califica explícitamente esa posibilidad como un "defecto" o "error" (doșa); la verdadera aportación de los nuevos teóricos radica en que, analizada desde una perspectiva epistemológica, esa identificación descansa en un error cognitivo. El deseo que experimenta por la heroína Śakuntalā este Dușyanta configurado imaginativamente (kalpita) con la anuencia del espectador absorto no sólo es ficticio, sino que se produce a costa de velar el alma misma (svātma) de tal espectador, y por lo tanto se trata, desde una perspectiva puramente epistemológica, de una forma de ignorancia: la ignorancia venturosa que llamamos experiencia estética.

Aunque Jagannātha no ofrece detalles que permitan identificar quiénes están detrás de dicha posición, su marcado énfasis en la subjetividad trae a la mente la centralidad que el tema tiene en su propia obra. Una persona puede experimentar belleza porque decide suspender el funcionamiento ordinario de sus procesos mentales y ceder el control a la imaginación. La experiencia resultante no sólo es distinta a cualquier otra; es distinta también en cada caso. El contenido específico del defecto cognitivo que llamamos imaginación variará en cada caso

\footnotetext{
${ }^{10}$ En especial, el tratamiento de Jagannātha recuerda la postura de filósofos como Dharmakīrti respecto a la percepción yóguica (yogipratyakșa) (AUTOR 2017, cap. 2).
} 
debido a la dimensión subjetiva que enmarca ese error. Cada quien imagina un universo propio. $^{11}$

Inmerso en su subjetividad, el espectador se identifica momentáneamente con el protagonista, permitiendo que sus sentimientos se fundan con los de éste en el delgado espacio donde confluyen ilusión y realidad. Él sabe que es y no es Duṣyanta, y con su imaginación apuesta por esta ambigüedad en el interés de vivir la dicha que depende de la misma. Así las cosas, la experiencia termina cuando el poder de bhāvanā cede: "[La experiencia estética] es pues el resultado de ese singular defecto [que llamamos bhāvanā], y por lo tanto aquella se diluye cuando éste desaparece" (Rasagañgādhara, p. 61).

Hay en todo esto un eco del discurso vedántico sobre māyā, aunque sin su carga condenatoria. El efecto de la actividad imaginativa es una especie de ilusoria superposición que no puede juzgarse como falsa o verdadera (anirvacanìya). La imaginación ciertamente entraña un misterio, pero, a diferencia de Abhinavagupta, no se trata ya de un misterio místico sino de uno epistemológico. Jagannātha concluye: "Definitivamente, ésta no es una experiencia ordinaria del amor, etc., pues en ese caso sería simplemente indispensable un sustrato objetivo. Se trata más bien de una ilusión (brahma)" (Rasagañgādhara, p. 66).

Jagannātha no niega que bhāvanā conduzca a una experiencia extraordinaria. De hecho, como vimos, insiste en ello. Esto no le impide, sin embargo, reconocer la frágil base epistemológica sobre la que descansa el prodigio, y, más aún, cancelar indirectamente, con base en esta misma exigencia lógica, la tentación de sucumbir al argumento metafísicoreligioso. La imaginación forma parte de una nueva economía que, basada en la suficiencia de la subjetividad y el funcionamiento del aparato cognitivo, no necesita postular su objeto en términos ontológicos.

Desde esta perspectiva, la discrepancia luce mucho más honda. La continuidad que, en pleno siglo XVII, Jagannātha otorga a las nociones de universalización e imaginación contemplativa presupone al mismo tiempo un abandono de sus implicaciones más exaltadas. Ciertamente, la imaginación es vindicada, pero dentro de límites muy precisos. Su poder es más terrenal.

Como afirman Gary Tubb y Yigal Bronner, sin negar el legado de Abhinavagupta y en cierto sentido afirmando la estructura heredada, los nuevos teóricos consuman con sutileza la transgresión: la experiencia estética no consiste más en remover un velo sino en imponerlo (2008, p. 625). De nuevo, en el caso de la imaginación, ello significa una contracción del

\footnotetext{
${ }^{11}$ La antigua teoría india sobre los residuos kármicos, alojados en lo profundo de la conciencia bajo la forma de impresiones que configuran nuestra personalidad, juega aquí su parte por encima de cualquier diferencia doctrinal.
} 
elevado estatus que la misma alcanzó entre los siglos IX y XI —trascendiendo de hecho el ámbito de la literatura - para recaer en el de mera fantasía o ilusión (brahma). Al mismo tiempo, sin embargo y a diferencia de quienes antes la juzgaron así, por ejemplo los filósofos del Vedānta, el tono de Jagannātha no es derogatorio. Después de todo, su análisis forma parte de un esfuerzo empático que se suma al de muchos pensadores en la misma tradición: legitimar la experiencia estética. Pero lo hace bajo supuestos completamente inéditos, notablemente con la neutralidad del historiador de las ideas. El resultado es una peculiar combinación del espíritu vindicativo de la antigua poética sánscrita y la prudencia normativa de los filósofos, sin llegar al extremo de unos (la mística) y otros (el rechazo), y afirmando en cambio los valores de su propia época y su propio horizonte intelectual: historicidad, subjetividad y, como veremos, relatividad.

\section{LA HUMANA RELATIVIDAD DE LA IMAGINACIÓN CREADORA (PRATIBHĀ)}

¿Y qué hay de pratibhā, el término con el que la poética sánscrita se pronunció acerca de los fenómenos de la inspiración y la imaginación, trasladando el universo visionario védico al ámbito de la creación literaria? ¿Qué función desempeña en la obra de Jagannātha? Y, más importante aún, ¿nos ofrece una perspectiva distinta a la alcanzada por el sendero de bhāvanā?

Jagannātha no ignora el tema, pues ello sería tanto como ignorar la tradición. Así, apenas unas líneas después de su definición inaugural de poesía, la misma que lo llevó, por sus implicaciones, a tocar el tema de la imaginación desde la perspectiva del receptor, emprende un esfuerzo explicativo similar, en busca de razones, pero desde la perspectiva de la imaginación creadora o pratibhā. La función causal asignada a pratibhā establece por lo tanto un lazo natural entre ésta y bhāvanā. Así, mientras bhāvanā es la expresión definitiva de esa atención concentrada que permite que una obra literaria despliegue todo su potencial estético, la primera denota una fuerza causal desde la perspectiva del creador mismo. Jagannātha la define así: "[Pratibhā] es estar en la presencia de palabras y significados apropiados para componer poesía" (Rasagañgādhara, p. 20).

Esta lacónica definición reitera el sentido y la función que la teoría literaria sánscrita le asignó a pratibhā siguiendo el ejemplo de la tradición visionaria védica. En particular, la idea de "proximidad" o "presencia inmediata" (upasthiti) remite a las de manifestación espontánea, inspiración e intuición. La imaginación es un mecanismo de revelación: hace aparecer los recursos lingüísticos que el poeta necesita y en ese mismo acto legitima el producto final. El 
sentido de continuidad que subyace a la historia de la imaginación en la India antigua persiste pues hasta el siglo XVII.

Empero, las discontinuidades surgen de nuevo apenas este consenso es sometido a escrutinio conforme a las preocupaciones epistemológicas de la época, y como parte del novedoso ejercicio de integración de ideas pasadas y presentes con el que Jagannātha aspira a ofrecer no sólo una explicación más completa sino asimismo afín a su horizonte intelectual. De entrada llama la atención el tono categórico y de exclusividad con el que pratibhā sirve al proceso creador: "La poesía tiene una sola causa: la imaginación al interior del poeta" (Rasagañgādhara, p. 20). Con esto, Jagannātha rechaza la influencia causal de cualquier otro factor y se distancia de la añeja tradición que ensalzó el poder de la imaginación a la par de fuentes como la formación (vyutpatti) y la práctica (abhyāsa), a veces defendiendo su necesaria concomitancia. En cambio, para Jagannātha pratibhā es, como resume Edwin Gerow, "un principio independiente" (1977, p. 288), y, aún más, una especie de meta-categoría.

Sin embargo, como podemos anticipar, la solución al viejo debate inaugura uno nuevo: el de la propia causalidad de pratibhā, algo que ningún teórico literario previo se había preguntado (Cahill, 1995, pp. 74-75). De este modo, el enaltecimiento presupone tanto una adherencia al pasado como un distanciamiento. Al final, como veremos, con esta estrategia Jagannātha abrirá un frente distinto de secularización de la imaginación.

La búsqueda de causas para pratibhā se concentra en tres opciones: factores invisibles (adrșta), y las ya referidas educación (vuytpatti) y disciplina (abhyāsa):

A veces tiene su origen en un factor invisible (adrsța), inducido por la gracia de una deidad o un gran ser, etc.; a veces [se debe en cambio] al entrenamiento especializado o a la práctica de componer poemas. Sin embargo, en modo alguno son [necesarias] las tres [causas al mismo tiempo] (Rasagañgādhara, pp. 20-21).

Hasta aquí una sola certeza guía la inédita búsqueda de causas para la imaginación creadora: la insuficiencia explicativa del modelo concomitante. Con ello Jagannātha reitera la necesidad de abrirse a un nuevo tipo de complejidad, menos sincrónica y más sensible a las diferencias; menos normativa y más consciente de sus determinaciones subjetivas. Un ejercicio sostenido en esa dirección es precisamente lo que encontramos en estas primeras páginas del Rasagañgādhara.

Entonces, en algunos casos basta la gracia para que haya imaginación, como lo sugiere el ejemplo de aquellos que hacen poesía sin haber recibido ningún tipo de entrenamiento, por ejemplo los niños prodigio (Rasagañgādhara, p. 21). Al mismo tiempo, el talento innato no es la panacea y bien puede suplirse, si llega a faltar, con aprendizaje y práctica, tal como lo 
demuestra el caso de aquellos que, tras haber perdido la inspiración, logran recuperarla gracias a una férrea disciplina:

Pero tampoco puede decirse que un factor invisible sea la única causa, pues todos somos testigos de que pratibhā de algún modo puede florecer gracias al aprendizaje y la práctica, incluso en una persona que por mucho tiempo fue incapaz de escribir poesía (Rasagañgādhara, p. 22).

Por supuesto, cabe asimismo la posibilidad de que el poeta reciba la formación adecuada, cuente con la disciplina requerida, y no obstante carezca de imaginación para escribir. La causa está presente, mas no su efecto. ¿Contradicen casos así el modelo multicausal? No, responderá Jagannātha. En algunos casos, la educación y el método quizá sean indispensables y sirvan como fuente exclusiva de inspiración; en otros, sin embargo, pueden no ser suficientes (Rasagañgādhara, p. 23).

Una vez más, el arte de ofrecer razones describe aquí un decidido giro por la pendiente de la subjetividad, pero lo hace además con un tono francamente relativista. Pratibhā depende ahora de muchos criterios, ninguno único. Cada persona es diferente; límites y virtudes varían en cada caso, y pratibhā no tiene porqué ser la excepción. En realidad, el único consenso en torno a los factores que permiten su surgimiento es más bien negativo, es decir, se fundamenta en la ausencia de impedimentos:

Por otra parte, [cuando hay educación y práctica, pero no poesía] no puede decirse que esto sea un defecto, pues bien puede postularse un tipo especial de pecado que actúa como inhibidor. De hecho, [atribuir] causalidad a la ausencia de obstáculos es algo en lo que todos coinciden (Rasagañgādhara, p. 23).

Indirectamente, sin embargo, con este consenso Jagannātha reconoce la fragilidad del fundamento en el que descansa pratibhā: la imaginación está expuesta a un sinfín de impedimentos. Por ejemplo, respecto a la buena fortuna (adrșta), si ésta se acepta como causa de la imaginación, es necesario aceptar entonces la posibilidad de un influjo contrario, también invisible pero negativo. Expuesta a la complejidad de la naturaleza humana, secularizado su alcance, la imaginación creadora no es un poder libre de vicisitudes. Detrás incluso de un poeta consagrado, reconocido por su gran capacidad imaginativa, está el ser humano, con una historia personal y, en última instancia, sujeto a la finitud: "Pues somos testigos de que incluso poetas que han escrito incontables obras dejan de hacerlo cuando algún rival, etc., les causa durante varios días una obstrucción lingüística mediante conjuros, etcétera" (Rasagañgādhara, p. 23).

En suma, también desde la perspectiva de pratibhā, hay algo irreduciblemente personal, subjetivo, en la imaginación, al grado que a la par de su ennoblecimiento como fuente única de 
la poesía, resulta imposible determinar qué inspirará a un poeta en particular (Shulman, 2012, p. 102).

Secularidad, subjetividad, relatividad son los valores que guían el discurso de Jagannātha. El efecto conjunto es, de nuevo, una imaginación articulada en términos puramente epistemológicos, fundamento suficiente para que la misma cumpla con sus fines estéticos, también ahora mucho más modestos: crear las condiciones para que el receptor sensible complete, con su propia cuota causal, con su bhāvanā, el hermoso entretejido ilusorio de la experiencia poética, ahí donde la ficción se justifica plenamente por mor de su profundo efecto y nada más, sin pretensiones metafísicas ni religiosas.

En suma, la original aportación de Jagannātha al tema se comprende mejor por lo que deja fuera: la dimensión trascendente. Juzgarla por lo que comparte con la tradición puede llevarnos a pensar, como hacen J. L. Patwardhan y M. V. Masson, que se trata tan sólo de una forma distinta, más rebuscada, a veces incluso ingenua, de decir lo mismo (1969-1970, p. 422). No es así. En este caso, las exigencias epistemológicas, con todas sus sutilezas y formalidades, no desempeñan una función meramente retórica; más bien encarnan una perspectiva radicalmente distinta, cuya pertinencia sólo puede apreciarse a la luz del peculiar horizonte intelectual que enmarca su producción, aspectos en los que aquí he intentado hacer hincapié, apartándome así de una evaluación normativa que califica la originalidad en términos puramente filosóficos, sin historia ni subjetividad: las dos grandes premisas del discurso secularizador sobre la imaginación con el que Jagannātha respondió tanto al pasado (el espíritu atemporal e impersonal de la tradición sánscrita) como a su presente (la atmósfera multicultural del siglo XVII).

Jagannātha abraza con honestidad el legado de Ānandavardhana y Abhinavagupta, y, al mismo tiempo, muestra un genuino compromiso con las necesidades intelectuales de su época. La combinación nos conduce a un paraje único. Quizá nada ilustre mejor ese paraje que la velada alusión, en el pasaje apenas citado, al iniciado tántrico, cuyos conjuros pueden arruinar la imaginación del mejor poeta. Como vimos, para Abhinavagupta la imaginación posee una estirpe religiosa y, en tanto tal, contiene un mensaje soteriológico que sólo el adepto tántrico es capaz de descifrar y encarnar; en Jagannātha, en cambio, la figura del tāntrika nos recuerda que la imaginación es un poder frágil, expuesto a la finitud, y en ese sentido, un evento humano, no divino.

\section{EPÍLOGo}


De acuerdo con el multicitado Sheldon Pollock, "algo muy antiguo murió con la muerte de Jagannātha, pero también algo muy nuevo" (2003, p. 96; 2001a , p. 405). En el primer caso, Pollock tiene en mente el debilitamiento de la tradición literaria sánscrita tras la muerte de Jagannātha, a menudo considerado su último gran exponente; en el segundo, se refiere a los aspectos que dan a su obra un sello distintivo - su espíritu crítico, su conciencia histórica, la epistemología como criterio último-, todos ellos enmarcados en el inédito horizonte cultural de intercambio entre las culturas mogola, sánscrita y, cabría agregar, vernácula.

Más allá de las radicales implicaciones del diagnóstico de Pollock, es decir, más allá de si el siglo XVIII marca el fin del ethos que permitió la existencia de la cultura sánscrita a lo largo de dos milenios, reduciendo su poder expresivo a mera repetición (2001a, p. 404), ${ }^{12}$ aplicada a nuestro tema aquí, la peculiar combinación de ocaso y esplendor significaría que con Jagannātha el antiguo discurso sánscrito alrededor de la imaginación experimentó un inusitado giro hacia un enfoque subjetivo e histórico que se aleja de la arraigada tendencia hacia la religiosidad notada por Edwin Gerow (véase antes p. 4).

El sentido de autonomía que ahora irradia la imaginación depende de una renuncia a cualquier pretensión teleológica más allá del ámbito propiamente literario; depende pues de un nuevo tipo de consenso: ser vindicada dentro y no al margen de los límites de la razón. Estamos, sin duda, ante un enfoque moderno, ya no sólo en el sentido que Jagannātha da a este término sino en un sentido general, con ecos más allá de los confines indios. Como he intentado sugerir, el aire de modernidad que emana de su teoría de la imaginación está íntimamente vinculado a un nuevo orden conceptual, cristalizado en la experiencia mogola y el efecto que ésta debió tener sobre las ideas de identidad y alteridad. La profunda sensibilidad de Jagannātha al cambio histórico, la relatividad de las ideas y la centralidad del sujeto así lo ponen de manifiesto. La articulación del tema de la imaginación a la luz de estas premisas puede verse entonces como una expresión de la respuesta que la cultura sánscrita organizó ante el cambiante entorno de la India bajo el dominio del islam.

Resta averiguar por supuesto si detrás de esta imaginación secular y subjetiva se agita la influencia directa de teorías persas y mogolas sobre la materia; o también, si el intercambio con la tradición vernácula india, que como se sabe gozó de tanto patronazgo como la sánscrita, ${ }^{13}$ fue un factor de influencia. Pertinente es asimismo la pregunta sobre un posible

\footnotetext{
${ }^{12}$ Para una crítica a esta postura, véase Hanneder 2002.

13 De hecho, para la segunda mitad del siglo XVII, durante el reinado de Aurangzeb, el apoyo a las tradiciones vernáculas al parecer adquiere preponderancia, relegando la producción literaria sánscrita a un segundo plano (Truschke, 2012, p. 318; Busch, 2010, pp. 272-284).
} 
reflejo a nivel de la propia praxis poética. ${ }^{14} \mathrm{~A}$ todo ello tendrían que dedicar sus empeños investigaciones futuras.

\section{Bibliografía}

Fuentes primarias

Ānandavardhana, Dhvanyāloka, with the Locana Commentary of Abhinavagupta, eds. Pt. Durgāprasād y K. Pāndurang Parab, Delhi, Munshiram Manoharlal Publishers, 1998.

Abhinavagupta, Tantrāloka, with Commentary by Rājānaka Jayaratha, eds. M. Rāma y M. K. Shastri, 12 vols., Shrinagar, Research Department, Jammu and Kashmir State, 1918-1938.

Bhāmaha, Kāvyālañkara, eds. B. N. Sarma y B. Upadhyaya, Benares, Chowkhamba Sanskrit Series Office, 1928.

Jagannātha Paṇditarāja, Rasagañgādhara. Text with English Translation and Critical Study, ed. D. Bhanja, Delhi, Bharatiya Kala Prakashan, 2004.

Jagannātha Paṇụitarāja, Bhāminīvilāsa. Critically Edited with English Translation and Notes, ed. H. D. Sharma, Delhi, Chaukhambha Sanskrit Pratishthan, 2005.

Jagannātha Paṇḍitarāja, Paṇụtarājakāvyasañgraha, ed. A. Sharma, Hyderabad, Osmania University, 1958.

Yāska, The Nighantu and the Nirukta of Śrī Yāskācārya. The Oldest Indian Treatise on Etymology, Philology and Semantics, ed. y trad. L. Sarup, Delhi, Motilal Banarsidass, 2009.

\section{Fuentes secundarias}

Athavale, R. B., "New Light on the Life of Paṇditarāja Jagannātha", Annals of the Bhandarkar Oriental Research Institute 48-49, 1968, pp. 415-420.

Busch, Allison, "Hidden in Plain View: Brajbhasha Poets at the Mughal Court", Modern Asian Studies 44-2, 2010, pp. 267-309.

Cahill, Timothy C., "Jagannātha's Rasagañgādhara. The Text with a Translation and Critical Study”, tesis doctoral, Universidad de Pennsylvania, 1995.

Chaudhuri, Jatindra Bimal, Muslim Patronage to Sanskritic Learning, Calcuta, Pracyavani, 1942.

AUTOR, La mirada anterior. Poder visionario e imaginación en India antigua, México, UNAM, 2017.

AUTOR, "El arte de la interpretación en la India sánscrita: orígenes y desarrollo", Nova Tellus 31-1, 2013, pp. 9-34.

\footnotetext{
${ }^{14}$ En cierta medida eso es lo que sugiere Shulman en el caso de la práctica imaginativa en el Sur de la India entre los siglos XV-XVII. Habría que averiguar si lo mismo vale para la India mogola. La sospecha de Shulman apunta en esa dirección: "Imposible borrar la impresión de que la pratibhā que describe Jagannātha refleja una profunda profesionalización y autonomía del oficio poético" (2012, p. 102).
} 
Friedmann, Yohanan, "Muslim Views of Indian Religions", Journal of the American Oriental Society 95-2, 1975, pp. 214-221.

Gerow, Edwin, Indian Poetics, ed. J. Gonda, Wiesbaden, Otto Harrassowitz, 1977.

Gerow, Edwin, "Indian Aesthetics: A Philosophical Survey", en E. Deutsch y R. Bontekoe (eds.), A Companion to World Philosophies, Londres, Blackwell, 1997, pp. 304-323.

Gonda, Jan, The Vision of the Vedic Poets, Delhi, Munshiram Manoharlal Publishers, 1984 (originalmente publicado en Leiden, Brill, 1963).

Halbfass, Wilhelm, India y Europa. Ejercicio de entendimiento filosófico, México, Fondo de Cultura Económica, 2013.

Hanneder, Jürgen, “On ‘The Death of Sanskrit”, Indo-Iranian Journal 45, 2002, pp. 293-310.

McCrea, Lawrence, The Teleology of Poetics in Medieval Kashmir, Cambridge, Massachusetts, Harvard University Press, 2009.

Patwardhan, Madhav Vinayaka, y Jeffrey L. Masson, "The Rasaganigādhara on the Definition and Source of Poetry", Journal of the Oriental Institute 19, 1969-1970, pp. 416-427.

Pollock, Sheldon, "What Was Bhața Nāyaka Saying? The Hermeneutical Transformation of Indian Aesthetics", en S. Pollock (ed.), Epic and Argument in Sanskrit Literary History, Delhi, Manohar Publishers, 2010, pp. 143-184.

Pollock, Sheldon, The Language of the Gods in the World of Men. Sanskrit, Culture, and Power in Premodern India, Berkeley, University of California Press, 2006.

Pollock, Sheldon, "Sanskrit Literary Culture from the Inside Out", en S. Pollock (ed.), Literary Cultures in History. Reconstructions from South Asia, Berkeley, University of California Press, 2003, pp. 39-130.

Pollock, Sheldon, "The Death of Sanskrit", Comparative Studies in Society and History 43-2, 2001a, pp. 392-426.

Pollock, Sheldon, "New Intellectuals in Seventeenth Century India", The Indian Economic and Social History Review 38-1, 2001b, pp. 3-31.

Shulman, David, More Than Real. A History of the Imagination in South Asia, Cambridge, Massachusetts, Harvard University Press, 2012.

Sjoman, Norman, “Jagannātha's Definition of Poetry: An Analysis of the Introductory Verses of Rasagañgādhara and the Definition of Poetry", Journal of Indian Philosophy 9, 1981, pp. 359402.

Truschke, Audrey, "Cosmopolitan Encounters: Sanskrit and Persian at the Mughal Court", tesis doctoral, Universidad de Columbia, 2012. 
Tubb, Gary, y Yigal Bronner, "Vastutas tu: Methodology and the New School of Sanskrit Poetics", Journal of Indian Philosophy 36, 2008, pp. 619-632. 